\title{
El hijo del Sud (1816), de Luis Ambrosio Morante: territoria- lidades de la Revolución de Mayo en clave pseudo-clásica
}

\author{
María Belén Landini \\ Universidad de Buenos Aires \\ belulandini@hotmail.com
}

\begin{abstract}
Resumen
En el marco del estudio de la obra conservada de Luis Ambrosio Morante (1772/1775/1780-1835) y de su vínculo con los procesos revolucionarios de Mayo de 1810 en Argentina, nos abocamos en este caso al tratamiento de El hijo del Sud, el único drama alegórico del dramaturgo. En particular, reflexionamos sobre la construcción de territorialidades a partir de una micropoética que propone el cruce de una archipoética española con el pensamiento iluminista de los jacobinos y cuyo protagonista es un "indio" que debe llevar a cabo la misión de liberar de la tiranía a su pueblo.
\end{abstract}

\section{Palabras clave}

Morante, drama alegórico, territorialidad, Revolución de Mayo, lluminismo.

\section{El hijo del Sud (1816), de Luis Ambrosio Morante: Territorialidades da Revolução de Maio em uma chave pseudo-clássica.}

\begin{abstract}
Resumo
No âmbito do estudo da obra conservada de Luis Ambrosio Morante (1772/1775 / 1780-1835) e sua ligação com os processos revolucionários de Maio de 1810 na Argentina, nós abocamos, neste caso, o tratamento em El hijo del Sud, o único drama alegórico do dramaturgo. Em particular, refletimos sobre a construção de territorialidades a partir de uma micropoética que propõe o cruzamento entre uma arquipoética espanhola com o pensamento iluminista dos jacobinos e cujo protagonista é um "índio" que deve cumprir a missão de libertar seu povo da tirania.
\end{abstract}

\section{Palavras-chave}

Morante, drama alegórico, territorialidade, Revolução de Maio, Iluminismo.

\section{El hijo del Sud (1816), by Luis Ambrosio Morante: territorialities of the May Revolution in a pseudo-classical style}

\footnotetext{
Abstract

In the context of studying the preserved work of Luis Ambrosio Morante (1772/1775/1780-1835) and its connection to Argentina's 1810 May Revolution, we focus on El hijo del Sud, the only allegorical drama written by this playwright. Specifically, we reflect on how the drama constructs territorialities through micropoetics that intersect classic Spanish lyricism with Jacobin Enlightenment philosophy. We also discuss the role of the protagonist, an "Indian" who assumes the mission of liberating his people from tyranny.
} 
María Belén Landini. El hijo del Sud (1816), de Luis Ambrosio Morante: territorialidades de la Revolución...

\section{Keywords}

Morante, allegorical drama, territoriality, May Revolution, Enlightenment. 
De los hombres del teatro revolucionario, es Morante, con toda seguridad, la figura más dúctil y de valores más acusados; se entiende que no enjuiciamos su obra con un criterio cerradamente literario; en este sentido, Morante es tan mediocre como todos los contemporáneos, pero, en el "oficio" teatral, era el único que poseía eso que hoy llamamos "dominio de la tabla"

(Berenguer Carisomo, 1947:171-172).

Teodoro Klein, en El actor en el Río de la Plata. De la Colonia a la Independencia (1984), titula su apartado número cinco "Morante. El revolucionario" y afirma que fue gracias a él que el teatro se convirtió en animador de la revolución. Morante comanda la primera cooperativa teatral que toma a su cargo la explotación de un coliseo. Según Klein, Luis Ambrosio Morante habría nacido en Buenos Aires en 1780, hijo ilegítimo de Domingo Ignacio Morante, mestizo, y Juana María de Rosario Molina, parda nacida en esclavitud. Juan Thames, en su texto de opinión "El origen de la bandera argentina como la conocemos hoy" (2018, 20 de junio), dice que no hay claridad respecto del lugar y el año del nacimiento de Morante, mientras que José Zapiola (1974: 144) ubica esos datos en Montevideo en 1722.

Profesionalmente se inició como apuntador o consueta para la temporada de 1799 en el coliseo de Manuel Cipriano de Melo en Montevideo, donde se había mudado su familia en 1793. En la época, los apuntadores que se daban cierta maña con las letras arreglaban y adaptaban los textos según las necesidades del elenco. Gracias a sus progresos, Morante fue llamado por Speciali, del Coliseo de Buenos Aires, para trabajar como apuntador, cantante y archivista, triplicando el sueldo que ganaba en Montevideo (Klein, 1984: 35). El primer documento donde se registra esto es de 1804 (Seibel, 2006: 51). José Luis Trenti Rocamora (1946: 171) cuenta que "[a] fines de mayo de 1803 ya se había formado la compañía cómica del Coliseo Provisional" en la que Morante era primer consueta y archivista. Esta sería la misma compañía que debutara el 10 de mayo de 1804, cuando se inauguró el teatro.

En 1805 ya habría dirigido El emperador Alberto de Antonio de Valladares y Sotomayor (Mogliani, en Pelletieri, 2005) y habría sido primer actor alterno. Su trayectoria de más de tres décadas lo destacó también como dramaturgo y, además, traductor de Hamlet y Otelo, de Shakespeare, entre otras piezas. En la defensa de la ciudad frente a las invasiones inglesas, Morante y otros actores, violinistas y músicos lucharon en los cuerpos de Pardos y Morenos. Blas Parera, el creador de la música de nuestro Himno Nacional, por su lado, combatió en el Tercio de Catalanes. Morante fue además un ferviente revolucionario de la causa de Mayo y puso el teatro al servicio de las ideas de los intelectuales que la defendían. En La semana de mayo de 1810, de Vicente López (comp.) y Larran de Vere (glosas) (1960: 40-48), se reproduce una carta de Buena Ventura Arzac a Mariano Orma en la que se narran los sucesos ocurridos en el Coliseo de Buenos Aires el domingo 
20 de mayo de 1810: Morante, contra las órdenes recibidas, decide representar Roma Salvada, encarnando el personaje de Cicerón. El cuerpo de patricios copó la sala para dar por terminada la función, pero los actores no sólo siguieron en escena, sino que, luego de terminada la tragedia, salieron del teatro llevando a Cicerón (Morante) en andas y festejando los revolucionarios parlamentos que acababan de sucederse.

En 1813, el Coliseo ya tiene diecinueve intérpretes, once actores y ocho actrices; a fines de ese año, Ambrosio Mitre, designado director del teatro, promueve a Morante a la dirección artística. En 1816, año de la independencia, se estrena El hijo del Sud, un acto con personajes alegóricos y música, firmado "L.A.M.", donde el estilo neoclásico se une a un anticipo del romanticismo, con los ideales de unidad americana. En 1818 se estrenan varias obras, entre ellas La ánima en pena, cuyo autor, que firma "Laureano Mortisombis" podría ser un anagrama de Morante (Seibel, 2006: 66).

El 30 de julio de 1821, al día siguiente de las honras fúnebres celebradas en honor de Belgrano, fallecido un año antes, se estrena en el Coliseo el "drama histórico" o "pieza militar" en dos actos, en verso, en el beneficio de Ana Rodríguez Campomanes, que lo dedica "al ilustre porteño". Se repone en 1833. El autor podría ser, una vez más, Morante, que hace el rol protagónico del general y designa el actor para cada personaje en el manuscrito original. Paul Groussac es el primero que le atribuye la obra. Para el 25 de mayo de 1821, se estrena Tupac Amaru, en cinco actos y en verso, firmado L.A.M. y protagonizado por Morante. Las crónicas de la época se lo atribuyen y, como pasaba con El hipócrita, lo aseguran partiendo de la predominancia de elementos dramáticos de la pieza. En 1825 y 1826 comparte el elenco en Buenos Aires con Trinidad Guevara y en 1827 vuelve a partir a Chile, haciendo en el camino una breve temporada en el Teatro del Cuartel de los Olivos de Ruiz Huidobro en Mendoza (Seibel, 2006: 77).

Si bien hasta ahora hemos consignado todas aquellas noticias en las que figura Morante como actor, director o dramaturgo, así como todas aquellas en las que la firma que figura en el texto es un anagrama de su nombre o las tres iniciales que coinciden con el mismo, es altamente probable que aún muchas más composiciones que le son atribuidas, aunque no haya datos suficientes para confirmarlo, sean de su autoría. Esto lo pensamos considerando el rol fundamental que cumplió en el teatro de su siglo y en la función política que este último tuvo durante los procesos sociales que se vivían en el Río de la Plata. Hemos hablado de los actos conmemorativos de la Revolución de Mayo, pero también sabemos que Al que le venga el sayo que se lo ponga, que Teodoro Klein atribuye a Morante, retrata muy bien la realidad que se vivió cuando el puerto de Buenos Aires se vio bloqueado por tropas portuguesas durante 1827.

Además de las obras que hemos citado en el desarrollo de este estudio, Margarita E. Grossman y Paula Castro (2008: 5) citan tres obras firmadas por Morante y 
conservadas al día de hoy en el Tesoro de la Biblioteca Nacional: Idamia o la reunión inesperada, de 1808; El refugio de amor en Chile, de 1824; y Tediato y Lorenzo o las noches lúgubres, también de 1824. Si bien la firma es de Morante, creemos necesario verificar si se trata de originales o de traducciones de obras europeas.

El hijo del Sud es un "acto alegórico con música" atribuido a Morante porque con su nombre coinciden las iniciales que cierran el manuscrito. El argumento narra el conflicto que el hijo del Sud enfrenta al tener que decidir entre el camino de la (falsa) Libertad y el camino de la Virtud, el primero bello y lleno de flores y el segundo yermo y gris. La Libertad y la Virtud, personajes alegóricos, le prometen triunfos y lo tientan con ilusiones, mientras el padre Sud lo arenga para que se decida a liberar a la Patria del yugo del tirano. Finalmente, toma el camino de la Virtud y llega, acompañado por ella y por la Libertad, y por intermedio de la Patria, al encuentro con la Inmortalidad.

Resulta interesante observar que, al uso de la crítica literaria de la primera mitad del siglo XX, Arturo Berenguer Carisomo (1947), al analizar El hijo del Sud, manifiesta abiertamente su desagrado frente a todos aquellos dramas que emulan las formas neoclasicistas. El teatro de la revolución, dice, necesita despegarse de lo español y, para esto, encuentra el teatro jacobino francés como ejemplo de los ideales de libertad y revolución contra la tiranía. El autor se indigna porque los intelectuales porteños no logran encontrar una forma propia. La emulación de retóricas ajenas, sostiene, no produce ningún resultado artísticamente feliz en nuestro territorio. Por otro lado, observa que la Sociedad de Buen Gusto de Teatro "se equivoca" cuando propone un teatro antiespañol, porque instala una censura y ninguna censura genera productividad de las formas artísticas.

Si bien Berenguer Carisomo habla puntualmente de lo que sucedía en el teatro, es importante ver que las ideas de Jean-Jacques Rousseau habían marcado a los intelectuales porteños a través de las políticas propuestas por Mariano Moreno. Es fundamental pensar en el pensamiento iluminista y racionalista a la hora de abordar El hijo del Sud, porque esta obra representa un quiebre en la macropoéti$\mathrm{ca}^{1}$ de Morante. En efecto, en las piezas que se conservan en la Ciudad de Buenos Aires, éste mantiene como constante en su dramaturgia el desarrollo de fábulas o sucesos que tienen que ver con la vida cotidiana o con coyunturas representadas por personajes en sus biografías particulares. En la obra neoclásica que nos ocupa, en cambio, se ve manifestado un pensamiento abstracto sostenido desde el racionalismo y que no se materializa en tensiones dramáticas, sino que alegoriza valores que estaban en circulación en el Buenos Aires de esa época entre los intelectuales que participaron de la Revolución de Mayo.

1. "La macropoética o poética de conjuntos poéticos resulta de los rasgos comunes y las diferencias de un conjunto de entes poéticos seleccionados [...]. Implica trabajar sobre realizaciones teatrales concretas, sobre individuos teatrales, por lo cual requiere el conocimiento previo de las micropoéticas [poéticas de un ente poético]" (Dubatti, 2008: 80). 
La pobreza estética que dice ver Carisomo se basa en que el texto intenta exponer una doctrina en forma teatral, pero carece de tensión dramática. No hay nudo más que aquella decisión que el personaje Sud debe tomar, pero que resulta evidente desde el comienzo de la obra, porque ya se sabe cuál es el mensaje que se intenta transmitir. "La censura española, caída en 1813 con la Asamblea famosa, se convierte, a poco andar, en una censura inversa: el teatro 'debe' ajustarse al canon revolucionario" (Berenguer Carisomo, 1947:1 59).

El hijo del Sud se representó en conmemoración del tercer aniversario de la Revolución de Mayo y en el mismo año en que se convocaba la Asamblea del año XIII. Morante, aunque influenciado por las ideas iluministas del círculo intelectual y letrado sabedor de, por lo menos, tres idiomas, no dejaba de ser un hombre de oficio. Había dedicado toda su vida a la escena en la que había empezado "desde abajo", como apuntador y consueta. La pieza que nos ocupa se sale de la práctica escénica y se enmarca en la literatura; una literatura absolutamente española en su forma retórica, pero que, al mismo tiempo, quiere ser francesa en sus ideas, cuyo efecto práctico buscará en territorio rioplatense.

Estamos hablando aquí de una transición, de un momento bisagra en la conformación de lo que será la nación argentina. Frente a la relevancia del rol del teatro y de quienes trabajaban allí en los procesos revolucionarios de Mayo, resulta atinado preguntarse por la conformación de territorialidades que se ven problematizadas en la obra de Morante, lo que haremos a través del discurso propuesto en los parlamentos de los personajes alegóricos de El hijo del Sud.

Territorializar es, al mismo tiempo, hacer propio el territorio y constituirse como sujeto individual en función de la relación con el espacio habitado y su comunidad (Hassner en Paasi, 2007: 1). En tiempos en que las ideas rousseaunianas proponen un contrato social que ponga al hombre americano a vivir bajo normas y derechos regulados desde un Estado, surgen las preguntas: ¿quién es ese estado? ¿Desde dónde y desde qué perspectivas se construye? ¿Quiénes forman parte de él?

Luis Ambrosio Morante es un personaje que encarna todas las tensiones sociales y políticas de la última etapa del Virreinato del Río de la Plata. Es mestizo, quizás nacido en Perú, en Buenos Aires o en Montevideo. Su prolífica dramaturgia deja en evidencia en los parlamentos de sus personajes la voluntad de delinear una territorialidad que nada tiene que ver con lo español metropolitano. Involucrado en la causa independentista, Morante intenta construir a través del teatro una identidad sudamericana. Su trabajo, en este sentido, pone en crisis el enraizamiento de la dramaturgia europea y española en América y propone una nueva forma de pensar la institución teatro y, a través de ella, el ser sudamericano.

Quizás, la apuesta más fuerte de Morante sea el cuestionamiento de lo español desde el interior de las archipoéticas y poéticas abstractas traídas de Europa y reproducidas "fielmente" en el Río de la Plata. Así como en otra ocasión hemos analizado el drama neoclásico y su estructura en Idamia o la reunión inesperada, en esta ocasión es el drama alegórico el que nos convoca. Mientras en España se 
materializan los valores eclesiásticos en la escritura de Calderón, en el Río de la Plata asistimos a la corporización de la Libertad, la Virtud, la Razón y el Sud.

Ponerle cuerpo (el cuerpo del actor) a estos personajes es darles las piernas necesarias para pisar un territorio, ese territorio que está en pugna, en contradicción, transición y transformación. Alegorizar es, justamente, ponerle cuerpo a algo, materializar algo que es abstracto. Ahora bien: materializar en texto a la Libertad o la Virtud nos remite al sentido semiótico de representación, un signo que reenvía a un referente. Sin embargo, cuando esa materialización sucede en el cuerpo de un actor, se hace necesario el abordaje de ese procedimiento a partir del "espesor de acontecimiento":

La unidad del cuerpo poético posee la capacidad de acontecer sin disolver las presencias originarias de las materias informadas: puedo ver la unidad pero también los materiales que confluyen en ella en su estadio anterior a la confluencia y/o atravesados por la afectación que la nueva forma les produce. Puedo ver al mismo tiempo el cuerpo natural-social del actor (material anterior a la nueva forma); el cuerpo afectado del actor (cuerpo natural-social en su entidad original pero tensionado por la nueva forma y la afectación del convivio); el cuerpo poético o la de-subjetivación del cuerpo natural-social en un cuerpo otro, el cuerpo de la nueva forma (Dubatti, 2012: 95).

Estos niveles se mezclan, se superponen, se cruzan. Cuando hablamos, además, de teatro fundamentalmente político, de un teatro que reivindica un pensamiento revolucionario, aparece en primer plano no solamente ese parlamento explícitamente militante, sino además la convicción de ese dramaturgo, director y actor que pone el arte al servicio de la política.

El hijo del Sud es un indio, un nativo americano al que su padre le aconseja elegir el camino correcto, guiándose por la luz de la Razón. Aparece allí, quizás, Morante, el mestizo interpelado por la intelectualidad naciente. Es importante ver, en relación con esto, que la Revolución de Mayo no fue una revolución popular. A diferencia de la Revolución Francesa en la que se inspiraron, los intelectuales porteños no contaban con una clase social nueva en el territorio que les pusiera la fuerza física y el apoyo popular a las nuevas ideas. El Plan Revolucionario de Operaciones de Mariano Moreno planteaba la necesidad de controlar al pueblo mediante el terror, proponía una dictadura en la que todo aquel que no siguiera los mandatos jacobinos fuera asesinado. Por suerte, Mariano Moreno no tuvo éxito en la Junta Grande en la que fueron representadas las provincias y, así, fue dejado de lado dicho plan.

Ahora bien: Morante propone, en un contexto de legitimación de la nueva forma de gobierno en Buenos Aires, la posibilidad de pensar de forma alegórica la identificación del Sur con el "indio". El hijo del Sud es un "indio" en el drama: la representación del espacio aparece aquí ligada directamente a una identidad y esa identidad, a su vez, se constituye a partir de la negación de un otro. El indio es "no-español". La Asamblea de 1813 prohíbe toda manifestación artística que no defienda los ideales revolucionarios, es explícitamente antiespañola. 
En la pieza, la construcción imaginaria de ese otro es, por negación o asimilación, la construcción de una subjetividad propia. En esta coyuntura en particular, además, la conformación de un yo está directamente ligada al territorio. Para empezar a saber quiénes son, esos personajes ( $y$, en consecuencia, los artistas involucrados) tienen que empezar por saber quiénes no son, a quiénes se asemejan o de quiénes se diferencian: ¿'son españoles o no lo son? ¿Son europeos (por extensión) o no lo son? ¿Viven en un territorio "prestado" por una monarquía remotamente lejana o son libres de sentir que su relación con el espacio los constituye?

El hijo del Sud, como drama alegórico, no trae aparejada la representación de una comunidad anclada a un territorio, pero sí la metáfora del camino, la elección entre el camino de la Virtud y el camino de la Libertad. La representación de esos dos espacios, de esos dos recorridos, remite a la simbolización o alegorización de ambos valores y a la forma en la que la dramaturgia construye el posible recorrido político de la incipiente nación. Ese recorrido incluye en El hijo del Sud la delimitación de un espacio simbólico identificado con el Sur, pero también con la República y con una teleología que apunta a la Gloria. El espacio simbólico del Sur, el hijo Sud, se opone a la Libertad porque, en el sentido del contrato social, esta Libertad es falsa. No hay bondades gratuitas disponibles sin precio alguno, no se llega a la Gloria o al objetivo republicano, a la independencia, a través de la Libertad, porque para los racionalistas la Libertad es solamente el estado natural, la naturaleza en sí misma. La Virtud, en cambio, es un camino difícil, quizá porque, de la mano de la Razón, implica la sumisión a reglas, a leyes, la lucha por llegar a algo glorioso, por el esfuerzo que significó, pero también porque reordena un caos e implica saber quién es cada uno en ese caos, de qué formamos parte, qué nación construimos. Dice Nicolas Bourriaud:

En su famoso ensayo Los condenados de la tierra, Frantz Fanon explica que la mejor arma del colono consiste en imponer su imagen por encima de la del pueblo colonizado. Resultaba necesario destruir aquellas imágenes intrusas para volver a encontrar, bajo la capa que las obliteraba, las de los pueblos en lucha por su independencia (2009: 37).

En ese punto estamos: las imágenes intrusas empiezan a destruirse, pero todavía no se vislumbra algo propio, sino más bien una mezcla de elementos que marcan un camino diferente. Ese camino yermo de la Virtud hacia la Gloria, el del indio que llega a la Inmortalidad, sólo tiene en su recorrido elementos prestados. Las postas de esta carrera son aquellas que los otros ya superaron y que, de algún modo, ahora nos tocan a nosotros. Es como si no pudiera construirse sobre el vacío, como si sólo se tratara de tomar de otros para poder construir un híbrido y ser eso que somos.

Aunque hay un lugar del acontecimiento teatral que podemos llamar "desterritorializado" y que correspondería a la poíesis (Dubatti, 2017), a la metáfora, a la construcción de un mundo poético, el vehículo del hacer teatral es, sin embargo, el cuerpo del actor. Ese cuerpo se ancla necesariamente en un territorio que forma parte de su proceso de subjetivación, entonces, ese mundo poético no puede 
sino encerrarse en el proceso de territorialización de los sujetos participantes. Producir territorialidades es subjetivarse. En relación con esto, es interesante también el concepto de sujeto radicante. El radicante, explica Bourriaud (2009: 57), se desarrolla en función del suelo que lo recibe, sigue sus circunvoluciones, se adapta a su superficie y a sus componentes geológicos: se traduce en los términos del espacio en que se encuentra. Por su significado a la vez dinámico y dialógico, el adjetivo "radicante" califica a ese sujeto contemporáneo atormentado entre la necesidad de un vínculo con su entorno y las fuerzas del desarraigo, entre la globalización y la singularidad, entre la identidad y el aprendizaje del Otro. Define al sujeto como un objeto de negociaciones.

El sujeto radicante es nómada y se presenta como una construcción, su eje es el movimiento, el itinerario que dibuja en el trayecto de los suelos sobre los que se desplaza antes de afincarse (si es que lo hiciere) en una identidad. Esa identidad está en constante movimiento. La construcción de un territorio depende de la relación del hombre con el espacio que habita (o recorre) y esa relación se modifica y cobra distintos sentidos a lo largo del tiempo porque, inevitable y necesariamente, el ser humano evoluciona. Esa evolución es causa y consecuencia del imaginario simbólico que se hace presente en el arte. Poder simbolizar y sublimar las propias necesidades humanas es parte del proceso vital. El teatro, en este sentido, encarna y pone maravillosamente en evidencia la imbricación total de cuerpo y mente humanas, la indisociación entre ambos, la necesidad de una mirada holística del hombre hacia sí mismo y hacia la sociedad. La relación de cada sujeto social con el espacio es la relación con los otros. Sin esta vinculación triangular, el ser humano no puede definirse: somos seres sociales y nos definimos e identificamos en la relación con nuestro hábitat:

Como individuo, el hombre es un fenómeno sospechoso cuyo derecho a la existencia cabe impugnar desde un punto de vista biológico, ya que biológicamente el individuo solo tiene sentido como ser colectivo o como parte integrante de la masa. Pero el punto de vista cultural le otorga al hombre una significación que lo separa de la masa y que en el correr de los siglos condujo a la formación de la personalidad... (Jung, 2008: 190).

Aquí es donde la alegoría de los caminos funciona como engranaje ideal del desplazamiento de Virtud y Libertad a valores posibles de ser encontrados en el indio, en el Sur. El sujeto consigo mismo y con el colectivo se crea, crece, se desarrolla, dentro o a través de una identidad móvil:

...lo radicante implica un sujeto: pero este no se reduce a una identidad estable y cerrada sobre sí misma. Existe únicamente bajo la forma dinámica de su errancia y por los límites del circuito que delinea, y que son sus dos modos de visibilidad: en otros términos, es el movimiento lo que permite in fine la constitución de una identidad. [...] Lo radicante difiere así del rizoma por su insistencia en el itinerario, el recorrido, como relato dialogado, o intersubjetivo, entre el sujeto y las superficies que atraviesa, en que se arraiga para producir lo que se podría llamar una instalación (Bourriaud, 2009: 61-63). 
Entonces, en el proceso de construcción de territorialidades en la obra de Morante, nos encontramos con la alegoría de los caminos. La coyuntura nos muestra un momento de transición, un punto medio de un recorrido en constante movimiento, uno de aquellos "botones" en los que el radicante (opuesto al rizoma) se detiene para luego seguir su camino, un camino incierto. Ese camino es, además de temporal, territorial, físico y concreto: es el camino de construcción de la subjetividad individual (de cada actor, de Morante como hombre de teatro, de cada ciudadano porteño) y de las identidades colectivas, es el camino en el que los vecinos dispersos en sus moradas se transforman en un ejército popular cuando se ven amenazados por una tropa inglesa en 1807, por ejemplo. Ese mismo camino es el que dibuja también el texto de la pieza en sus formas retóricas españolas, en su estilo neoclásico y en sus ideas jacobinas. Con todo esto se está buscando un camino. Aunque con elementos prestados, lo que está en proceso es algo nuevo, híbrido, en conflicto y caótico, pero, en definitiva, propio.

\section{Referencias}

Berenguer Carisomo, A. (1947). El Neo-clasicismo jacobino. Las ideas estéticas en el teatro argentino. Buenos Aires: Instituto Nacional de Estudios de Teatro, 111-126.

Bourriaud, N. (2009). Radicante. Buenos Aires: Adriana Hidalgo.

Dubatti, J. (2012). Introducción a los estudios teatrales. Propedéutica. Buenos Aires: Atuel.

Dubatti, J. (2008). Cartografía Teatral. Introducción al Teatro Comparado. Buenos Aires: Atuel.

Castro, P.; Grossman, M. (2011). Teatro americano: un tesoro de la Biblioteca Nacional. En: Barber, E., comp. VII Encuentro Internacional y III Nacional de Catalogadores: Estándares y procedimientos para la organización de la información. Buenos Aires: Biblioteca Nacional.

Jung, C. (2008). Símbolos de transformación. Buenos Aires: Paidós.

Klein, T. (1984). El actor en el Río de la Plata. De la Colonia a la Independencia. Buenos Aires: Asociación Argentina de Actores.

López, V. (comp.); de Vere, L. (glosas). (1960). La semana de mayo de 1810. Buenos Aires: Atlántida.

Morante, L. A. (1827). Al que le venga el sayo que se lo ponga. Manuscrito inédito.

Morante, L. A. (1924). El hijo del Sud. Buenos Aires: Instituto de Literatura Argentina, Facultad de Filosofía y Letras, Universidad de Buenos Aires.

Moreno, M. (1915). Escritos políticos y económicos. Ordenados y con un prólogo por Norberto Piñero. Buenos Aires: La Cultura Argentina.

Paasi, A. (2007). Territory. En: Agnew, J.; Mitchell, K.; Toal, G.; eds. A Companion to Political Geography. Oxford: Blackwell Publishing, 109-122. 
Pelletieri, O. (dir.) (2005). Historia del Teatro Argentino en Buenos Aires. El período de constitución (1700-1884). Buenos Aires: Galerna.

Seibel, B. (2006). Antología de obras de teatro argentino desde sus orígenes a la actualidad. Tomo I (1800-1814). Sainetes urbanos y gauchescos. Buenos Aires: Instituto Nacional del Teatro.

Thames, J. (2018, 20 de junio). El origen de la bandera argentina que conocemos hoy. Infobae (sitio web). Recuperado el 25 de noviembre de https://www. infobae.com/opinion/2018/06/20/el-origen-de-la-bandera-argentinaque-conocemos-hoy/.

Trenti Rocamora, J. (1947). El teatro en la América colonial. Buenos Aires: Huarpes.

Zapiola, J. (1974). Recuerdos de treinta años (1810-1840). Santiago de Chile: ZigZag. 